\title{
FAMILY DISORGANISATION AND MENTAL HEALTH IN A SOUTH AFRICAN MINING COMMUNITY
}

\section{Chenga, F Cronjé}

\section{INTRODUCTION}

Family disorganisation and mental health in mining communities in South Africa are not unique, but it is the unique nature of mining communities that creates the risk factors and the types of service provisions that exacerbate the vulnerability of these communities (Gylfason, 2001). At the same time, it is the nature of mental health that makes it a largely ignored health problem in these communities. These are burning and relevant issues and the focus of this article.

A discussion of family disorganisation and mental health issues in the South African mining communities would not be complete without looking at the political history of the sector and the subsequent power relationships between the mining corporations, government and communities. Mbendi (2002) suggests that in order to get a better understanding of the political history of the sector it is important to look at the historical background of migration in the mining industry. Schoofs (1999) argues that the scale of mining explains why the draconian system of migrant labour was imposed, which in turn paved the way for apartheid. To maintain profitability, the mining industry required cheap labour and consequently looked beyond its borders. In addition, he argues that white labour, imported for their mining skills and experience shortly after gold was discovered in 1886, saw black workers as a threat to their relatively high wages. To combat this threat, the white unions, amongst other things, forced the industry and then government to adopt the "colour bar", banning black workers from skilled jobs, and prevented black families and black workers from settling permanently in mining towns. These policies were the forerunner of the apartheid system. The impact of these policies on the social and economic conditions in mining communities has been identified as the major risk factors associated with family disorganisation and mental health problems in these communities.

The unique characteristics of the mining environment in South Africa are that mining communities are mainly isolated, originally rural with high illiteracy rates, and as a consequence they become very dependent on the mining companies for their livelihood and development. The rural-oriented environment often becomes barren and is associated with an ugly landscape as a result of large-scale excavation. In addition, communities are often exposed to toxic environmental hazards from mining operation wastes (Unsted, 2001). Mining is by its nature a temporary activity because of its dependence on the available mineral deposits. It is also fast growing and is associated with high earnings for the mining corporations, which have an impact on the local communities who are usually unable to respond to this across-the-board momentum due to their rural-based background. Consequently the local population experiences culture shock and do not respond effectively to the developmental changes, occupational skills requirements, and the rapid change from an agriculturally-based society to a cash-dependent environment (Chenga, Cronjé \& Theron, 2006:59). This has in most cases resulted in companies depending heavily on labour from elsewhere.

The consequence of this has been that the overpowering impact of the mine, together with the political transformation in 1994, has emasculated the social structures to the extent that most of 
the traditional hierarchies become symbols of authority rather than functional authorities (Meyers, 1999; Mohale, 2001; Van Wyk, 2004). The extreme measures taken by some of the community members to cope and adapt to the changes are reflected in some of the behaviours that result in family disorganisation and mental health problems in these communities. Against this background, what is often observed when looking at South African mining communities include:

- loss of livelihood, i.e. from agricultural to cash-dependent societies that employ mainly men;

- vast social inequalities between the poor and the wealthy;

- high rates of unemployment;

- underdeveloped communities, neither rural nor urban in nature;

- closed and isolated communities;

- high prevalence and incidence of communicable and poverty-related diseases such as HIV/AIDS, TB and malnutrition in children;

- high levels of hopelessness amongst the local population with regard to the future;

- high influx of migrant labour;

- inadequate and overcrowded public services such as health and social services.

Despite the new political dispensation in 1994, these social and economic conditions continue to persist in the mining communities. Globally and nationally, there has been pressure on corporations to become more corporately accountable for their actions in the communities where they operate (Mineral and Petroleum Resources Development Act, 2002; Broad-Based Socio-Economic Empowerment Charter for the Mining Industry, 2002 - hereafter cited in text as the Mining Charter). This entails that companies not only focus on the profitability and production of the company, but also direct the focus of their core business to corporate social responsibilities, which implies being involved in sustainable development in the communities.

Historically, the lack of environmental, social and economic regulation has had a direct impact on the health and welfare of people and communities, and obviously also impacts on the environment itself. Although stringent regulations have been introduced in recent decades, the legacy of health and welfare problems associated with mining remains prevalent (Packard, 1989).

The issues raised in this article are the result of research undertaken at a specific platinum mine in the Rustenburg area in the North-West Province of South Africa. The scope of the family disorganisation and mental health issues under discussion relates mainly to the communities around the mine operations and not the employees, except where interaction with the communities results in these problems.

\section{OBJECTIVES}

Against the above mentioned background, the main objectives of this article are to:

- assess some factors (migrant labour, poverty, HIV/AIDS and infrastructure) that increase the vulnerability of mining communities to family disorganisation;

- identify the mental health issues raised by the communities in relation to family disorganisation;

- discuss the mental health provisions and access to them in the mining communities; 
- make some recommendations with regard to factors causing family disorganisation and mental health problems by also looking at concepts of social responsibility and accountability of the various role players.

\section{RESEARCH METHODOLOGY}

The vast majority of the communities in this survey are underdeveloped and semi-rural with a very low literacy level. This means that a quantitative research method was unsuitable and would not produce the comprehensive results that a qualitative research method would bring.

The qualitative method is a better choice for the subject matter in that it enables the participants to expand on their answers without being limited by the questions. Data collection methods included mainly focus groups and interviews. Focus groups (8-12 people) and interviewees were selected purposely to take account of gender, race, migrant or local status, age and specific interest groups, such as health personnel, migrant groups, etc. (Miller, 2000:400-401). Additional individual participants (e.g. local pharmacist) and other interest groups (e.g. church leaders) were identified by the researchers as the research progressed. Some individuals in the area were also used as key informants (e.g. community representatives). Patton (2002:321) describes key informants as "people who are particularly knowledgeable about the inquiry setting and articulate about their knowledge - people whose insights can prove particularly useful in helping an observer understand what is happening and why." These have been also included in the sample. According to the researchers, the research group ("sample") was a fairly good representation of the research universe. To enhance the scientific nature of the study, two researchers and a translator were necessary, who facilitated each focus group and personal interviews. Additionally, the researchers also made use of objective observation to "collect" data. Creswell (1994:150) noted two main advantages of observation: it is firstly very useful to register unusual aspects, and secondly it is useful in exploring topics that may be uncomfortable for participants and informants to discuss.

The researchers conducted thirty focus group interviews and forty personal interviews. With this sample, the researchers tried to include as many interest groups and individuals as possible in the research setting. Focus group interviews with the following groups were conducted:

- Agricultural project of the mine (Itereleng) - Migrants (mixed gender, black)

- Agricultural project of the mine (Itereleng) - Workers (mixed gender, black)

- Agricultural project of the mine (Plantinum) - Workers (male, black)

- Bapong community (mixed gender, black)

- Church leaders (mixed gender, mainly white with two blacks)

- Counsellors (mixed gender, black)

- Farming community (mixed gender, white)

- Grace Care Centre residents (women, mainly white with one black)

- Health volunteers - Segwaelane (women, black)

- Hostel crèche - Women (black)

- Hostel residents - Male migrants (black) Group 1

- Hostel residents - Male migrants (black) Group 2

- Majakaneng community (mixed gender, black)

- Majakaneng women - Volunteer group (black) 
- Marikana community (mixed gender, black)

- Marikana community women (mixed: migrants and locals, black)

- Marikana crèche - Women (black)

- Migrant wives from Eastern Cape visiting Segwaelane (black)

- Modderspruit community (mixed gender, black)

- Mooinooi women - Volunteer group (white)

- Segwaelane community (mixed gender, black)

- Segwaelane - Male migrants (black) Group 1

- Segwaelane - Male migrants from Maputu (black) Group 2

- Sonop community group - Volunteers (women, black and white)

- Sonop Primary School - Teachers (black and white)

- Traditional healers (mixed gender, black)

- Volunteer group assigned to the Development Trust of the mine (mixed gender, black and white)

- Women from Eastern Cape in married quarters (black)

- Wonderkop - Elderly group (mixed gender, black)

- Wonderkop youths (mixed gender, black)

The focus group questions/discussions were very "open", broad and relaxed; examples of these open questions that lead to open discussions were: Why did you [migrants] come to work at the South African mines? How do you find it here [at the mine]? How are your working conditions? What do you do when you are not working? Tell me about your family set-up? Questions in the personal interviews were also quite open, but obviously more specific according to the background (e.g. clinic nurse, medical practitioner, hostel manager, community member etc.) of the participant. The most important facet in all the interviews (focus groups as well as personal interviews) was that the participants should describe the world in which they live. According to his/her spontaneous response and descriptions, participants can/may discover new contexts and relations that can be used by the researcher for meaningfully interpreting the results (Kvale, 1983:180-183).

In general the researchers were well received in the different communities and the responses from the focus groups as well as the personal interviews, as already mentioned, were very open, spontaneous and honest. Translators were used because the communities in the study speak various languages, e.g. local languages (Tswana, Xhosa, Afrikaans and English) as well as Fanagalo (which is a fusion of all the languages used in the mining milieu) and migrant languages (including Shona, Shangaan and Sotho). In addition, the ethnic and cultural mix of the researchers also contributed positively to the understanding of the issues involved.

The interviews with the participants were translated where necessary and transcribed. The translated version supplied information that was qualitatively interpreted by the researchers. For the analysis and interpretation of the results, a selection of statements on central themes (e.g. migrants, HIV/AIDS, etc.) was compiled for the commentary. A more theoretical - as opposed to a practical - approach was then used for the analysis of the data. The researchers drew upon the insights from the interpretation of written texts in the humanities (literature survey) and then re-contextualised the data within the specific theoretical framework (Kvale, 1983:179-180). 
According to Guba (Krefting, 1991:215-217), four important elements will increase the trustworthiness of qualitative and quantitative research.

- Truth value (confidence in the truth of the findings and the context in which the study was undertaken). The researchers were very confident about the truth of the findings based on the above-mentioned research design, informants'/participants' contributions and context. Such accurate descriptions of human experiences were given that people who also share that experience will immediately recognise the descriptions (see Sandelowski in Krefting, 1991:216).

- Applicability (the degree to which the findings can be applied to other contexts and settings or with other groups). Although generalisation may be somewhat of an illusion in qualitative research, most of the findings in this study fit into some other mining contexts in South Africa (where the researchers have also conducted research, e.g. in the Limpopo Province) outside this study situation.

- Consistency (whether the findings would be consistent if the inquiry were replicated with the same subjects or in a similar context). Qualitative research emphasises the uniqueness of the human situation, so that variation in experience rather than identical repetition is sought. Explainable sources of variability in replicated studies might include increasing insight on the part of the researcher, informant fatigue, or changes in the informant's life situation.

- Neutrality (the degree to which the findings are a function solely of the informants input and conditions of the research and not other biases). Qualitative researchers (also in this study) try to increase the worth of the findings by decreasing the distance between the researcher and the informants, e.g. by prolonged contact with the informants or lengthy periods of observation. Lincoln and Guba (in Krefting, 1991:217) suggest a shift in the emphasis of neutrality in qualitative research from the researcher to the data.

The researchers tried their utmost to guide their research and material according to these elements during the study.

\section{FACTORS LEADING TO FAMILY DISORGANISATION}

The following are some of the main factors identified from the research that contribute to family disorganisation in the mining communities:

- Migrant labour

- Poverty and unemployment

- HIV/AIDS

- Infrastructure.

\section{The migrant labour system}

Different sources estimate that the number of immigrants working in the South African mining sector as far more than $50 \%$ - the mine in the research setting is no exception (Mbendi, 2002). By far most of the migrants come in unaccompanied and many of them live in singlesex hostels; this is a situation which is of serious concern when taking account of the current health, welfare and social issues in the world, especially in Africa.

The impact of the migrant labour system on the welfare of children and family in the mining communities is the consequence of the type of migration models and the environment that the migrants find themselves in after migration. Bekker and Swart (2003:63) suggest that there are 
three models that often appear in the analysis of migration in South Africa: circulatory migration, oscillating migration and gravity migration. In terms of the labour migration that prevails in the mining industry, the oscillating migration model is the most pertinent in terms of creating family disorganisation. Oscillating migration refers to labour migration: where an adult moves in search of a job, returns to the rural home after this job has been completed and then repeats the cycle. The individual often undertakes this form of migration without the family. Some of the high-risk situations that the migrant find in his new environment include: overcrowded and poor single-sex hostels, harsh working conditions, hostile and desperate surrounding communities with a strong dependence on the miner's income, and poor recreational facilities.

As already stated, the most important issue in this regard is that migrants are unaccompanied when they come over to work at the mines. This has in most cases resulted in "second families" being created in the new hosting communities. The consequence of this practice is that there are a lot of single-parent families resulting from men "moving on". Obviously, the "real family" in the "sending" communities also suffers from this situation. Although not all migrants have "second families", many of them have to resort to sex workers, which can have a very negative impact on the community's social structure. This also impacts on the financial status of the migrant labourers, who have to feed two families on very low income. TEBA (a financial institution that provides financial services to mine labourers) reported that a lot of migrants waste their money on, for example, women and alcohol. As a consequence TEBA has experienced a lot of complaints from wives in the "sending" communities, who state that the men are not sending them any money. However, there are some migrants who are looking after their families well "back home" by sending them money on a regular basis (Cronjé, Chenga \& Naudé, 2005:22). The impact on family disorganisation is that women and children are often neglected and rely upon relatives or the state to care for them by providing food parcels. This often leads to stress within the family, which can often lead to violence and never-ending arguments, which in turn impact on the mental health of family members.

\section{Poverty and unemployment}

The stresses of poverty (e.g. unemployment) can result in a vicious cycle where the head of the family loses his self-esteem, deals with this by resorting to alcohol, which in turn normally leads to family violence and consequently family disorganisation. The "Family Stress Model" of Conger, Conger, Elder, Lorenz and Simons (2000) stresses that poverty is one of the most important factors that can put severe strains on relationships, bring about depression and family disorganisation (Shahab, 2005:1). Organisations approached in this study such as care centres, churches and traditional healers all confirmed that this cycle is most prevalent in the lives of people that turn to them for help. The rapid change from rural societies to moneybased societies creates social problems, especially for women, youths and children. The displacement of people from rural communities,, where people have been able to fend for themselves for basic needs (e.g. food), has a serious impact on issues such as food security, because the mining operations drastically change the nature of the communities and take away the agrarian land from communities. Communities are now characterised by high cash dependency, with no informal activities relating to extra income-earning projects, such as cottage industries, backyard vegetable gardens, etc. Consequently, the levels of poverty are related to the employment status of the community members. Opportunities for women are very limited in mining communities. This scenario is not sustainable, as women are known to play a significant part in reducing poverty at household level as well as in the community (Russell \& McDonald, 1982). 
Consequently some women take up prostitution as a way of earning an income to feed themselves and their family. In addition, there were reports from the participants that some women have offered their children to men in order to get continuous financial support for the family. This can be interpreted as a subtle form of prostitution and obviously child abuse. Complaints are that girls of school-going age are increasingly getting involved in prostitution and are out of the parents' control. Several women reported that when women apply for work at the mines, they encounter "sex for jobs" policies instituted by the recruitment officials. In some desperate situations teenage girls have resorted to becoming pregnant in order to qualify for child support. The Department of Health reported that teenage pregnancies in some parts of the North-West Province have increased by $90 \%$ over the past few years. Their concern was the possible relationship between teenage pregnancy and receiving child support by the mothers (Du Preez, 2004:13). The implications of these risk factors are that it leaves the women even more vulnerable, consequently creating more demands on an already unstable welfare system.

\section{HIV/AIDS}

One cannot talk about family disorganisation and mental health in Africa, and specifically South Africa, without looking at the impact of HIV/AIDS on people's social, economic and psychological experiences. According to the recent scenario report of UNAIDS, a sombre picture of the impact of the disease has been painted for the next twenty years in Africa, despite efforts and strategies from governments, international help organisations and the private sector (De Villiers, 2005:4). Unicef reported recently that about $80 \%$ of the 15,2 million children world wide who lost one or both parents to HIV/AIDS, live in Africa south of the Sahara (Mulder, 2007:12). In addition, the Medical Research Council (MRC) reported recently that about fourteen times more people are dying of HIV/AIDS than that the findings of Statistics South Africa (SSA) suggest. According to the MRC, nearly $30 \%$ of deaths due to "natural causes" are caused by HIV/AIDS; the corresponding figure for SSA is 2,8\% (Rossouw, 2005:6). The following are some of the disturbing facts about HIV/AIDS in the mining sector in South Africa:

- According to a survey $62,0 \%$ of the mining sector in South Africa's profit margin has been affected by HIV/AIDS through loss of productivity, absence of the workforce and an increase in the cost of worker benefits (Le Roux, 2004:1);

- The same survey estimates that about 33,0\% of the workforce of the Anglo Gold and Harmony mining groups is HIV positive. This corresponds with figures from the mine in the research setting, which found that a quarter of its employees were HIV positive (Metcalfe, 2003/2004:72).

HIV/AIDS issues are not unique to the mining sector; however, the prevalence and incidence of the disease are exacerbated by some of the following characteristics of the mining environment: migrant labour, social structure, the poor infrastructure and HIV/AIDS programmes (which provide ART for male employees but not for their dependents).

The main welfare and family disorganisation issues within the mining communities as a result of HIV/AIDS are: child- and/or grandparent-headed families, AIDS orphans and the impact on mental health.

The increasing rate of child- and/or grandparent-headed families in Africa as a result of death from HIV/AIDS is alarming (Mulder, 2007). However, as indicated above, the nature of mining communities as well as the migrant labour system can be conducive to a high incidence of child- and grandparent-headed families. The problem for the survivors is that, by its nature 
HIV/AIDS is a slow painful death, which requires intensive care in terms of feeding, hygiene and emotional support. Furthermore, it is shrouded by secrecy, making it difficult for the carers to seek support. In most cases it is the children who look after both parents until they die. These children have to pick up the pieces after their parents die. For migrant children, especially, the problem is more severe because they are not entitled to child welfare benefits or support from the social support services as their South African counterparts are. The result of this is that either the children return to the "sending" communities, where they are going to be treated as strangers or fend for themselves as street kids with all that comes with that. These situations help to feed the HIV cycle. Although the elderly receive pensions, most are unable to use the money for their own needs. Most are appointed as foster parents for AIDS orphans; they therefore take on the difficult responsibility of looking after children, which entails (amongst other things) ensuring that the children attend school. Reports from participants in the study found that, because of the grandparent's inability to control and discipline, the mining communities are characterised by a high rate of school drop-outs. Therefore, grandparents require more than just financial support to deal with the situation. This system (families headed by the elderly) ignores the fact that older people are also at risk of becoming infected. Voluntary tests in Uganda found that one in every five people over 50 years old was HIV positive (Help Age International, 2004:6, 7, 9).

The alarming increase in the rate of AIDS orphans speaks for itself. Unicef has reported that South Africa has about 1,1 million AIDS orphans (the highest number in the world) and that there are more than 40000 child-headed families (Brits, 2004a:6).

\section{Infrastructure}

Basic infrastructure in the communities generally refers to services such as the transport networks, access to school, sport and leisure facilities and other basic services such as electricity and water. The major impact on family disorganisation in terms of infrastructure in the mining community is the lack of recreational facilities. Throughout the study the theme that was echoed by all groups in the community was boredom. The study found that lack of recreational facilities resulted in high and early dependence on illicit substances such as alcohol and drugs. This has its own impact on risky sexual behaviour. Campbell and Mzaidume (1999) found that the level of HIV infection varied among different networks of people: members of church and sports groups had lower levels of infection; people in savings clubs had higher levels as a result of generally having more sexual partners and a higher level of alcohol consumption.

More specifically, the housing conditions are very poor. There is a serious shortage of adequate housing, with an estimated $80 \%$ of the population living in tin shacks (poorly constructed corrugated sheds) as their permanent home. Initially some of these tin shacks were set up by migrants, but in some areas the tin shacks accommodate both the local people and the migrants. The poor housing conditions have been blamed for, amongst other things, the increase in the spread of disease because of overcrowding. In addition, these poor housing conditions also lead to family disorganisation and early sexual experiences for the young, because in some instances a shack can house three to four families and at times they are separated only by curtains. According to the minister of housing, the government is committed to a housing programme with a target of doing away with shacks in ten years time (Rossouw \& De Lange, 2004:5). The local authorities in the research setting reported that they face a dilemma, because they have the money to build the houses but the land belongs to the mine. Consequently, they are unable to meet the targets. 
The impact of family disorganisation on mental health issues in the mining communities will be discussed below.

\section{MENTAL HEALTH IN THE MINING COMMUNITIES}

According to Harpham (1994) the main social risk factors for mental ill health are long-term difficulties, negative life events and lack of social support to buffer, or reduce, the effects of such difficulties and events. Examples of long-term difficulties include poverty, inadequate education, living in a hazardous physical environment and high levels of insecurity (violence and accidents). Examples of negative life events include separation from partner, loss of employment and forced migration. Changes in social support can occur with phenomena such as urbanisation, which may lead to a reduction of extended families, an increase in singleparent households, age-specific rural-urban migration and under- or unemployment. This description epitomises the conditions found in the mining communities.

The following are some of the mental health issues raised during the research.

\section{Employment-related mental health}

Most reports about poor mental health at work are related to stress. Staff members, members of the communities and mine management, reported that the main forms of poor mental health were depression, suicides and attempted suicides, and alcoholism. There were various reasons put forward as explanations for this. For the white staff members it is usually job security issues. One manager stated that: "since the beginning of the Equity in Employment the white staff members have been finding it difficult to feel secure in their jobs." At the same time, newly promoted black managers also experience stress as a result of the treatment they get from other work colleagues. A senior manager reported that the promotion of blacks has resulted in friction amongst the races. He said that "friction is present and people just do not mix". Situations like these can be stressful for the black manager, if the rest of management is not supportive or there are no other black managers to share his experiences. In addition to these issues, people were experiencing financial and family problems. One manager blamed the financial problems being experienced in the work place on the easy access to loans. He stated that people are over-committing themselves. Some in the lower occupational positions are borrowing from the "loan sharks" and the pressure that they impose for repayments is driving some of the employees to suicide. One staff member suggested that there had been several suicides in the year of the research and he suspected that some of the accidents that take place underground are the result of stress (also compare Bildt \& Michelsen, 2002). At home this work-related stress manifests itself in the form of high alcohol consumption and violence against women and children.

Family issues are also prominent amongst the mine employees. One migrant worker expressed the view that it was necessary to work and live so far from the family, but it is difficult: "we experience stress and there is nothing that we can do. We get to a point that we worry and this affects our work. Sometimes you receive news that your child is ill or something serious has gone wrong, but you just get stressed. You feel so helpless because sometimes you won't even have the money to send home. You just don't bother to tell the managers because surely they can tell when someone is experiencing stress but they prefer to do nothing. Although sometimes they help by lending you cash but it does not really help with the stress. Another problem is that when someone has died at home, the company does not release us. They do not understand our cultural needs." 
Such difficulties, although experienced by men at work, result in the lack of support for women at home and also have an impact on the mental health of the family left behind.

\section{Mental health and gender in the mining communities}

Both black and white women reported depression, stress and alcoholism as the main mental health problems. The white women were initially uncomfortable about discussing the issue of mental health in their communities. They acknowledged that there is a lot of depression and alcoholism amongst the wives of mine workers. The main reasons put forward were loneliness and boredom.

In the mining environment, when people talk about migrants, they are usually referring to the black lower occupational positions. The migrant nature of the mine occupations also affects the whites in the higher positions and impacts on family relationships. The white women reported that when they come to a new place, they find it difficult to make friends and one of the reasons for this is that friendships are usually based on the occupational position of the husbands. Therefore some women are compelled to socialise with people for the sake of their husbands. Consequently, as was stated by one of the female participants, "women in these communities are not comfortable discussing their personal life." There is a fear that personal issues may impact on the husband's position at work, especially if it relates to alcohol use. Therefore the wives tend to keep quiet and remain isolated. This can have a negative impact on the support networks for these women. One of the mine doctors stated that "mining communities are artificial communities; the artificiality itself can be a problem." Mining communities are traditionally gender insensitive, especially when it comes to issues relating to employment and recreational facilities for women. This exacerbates the potential for mental health problems for women. Both the black and white women reported experiencing alcohol problems, either as a result of the husband's alcohol use or use by the women. The women reported that some of these problems were linked to mental health problems within their communities. Some of these alcohol-related problems included sexual abuse, violence towards women and children, loss of financial control and womanising.

Black women were disproportionately affected by issues such as finance, second families and unemployment, because of the poor socio-economic conditions they live under. Consequently, there were more mental health problems reported as a result of these conditions. For example, there were several cases of suicides by hanging amongst the migrant black women frustrated as a result of finding their husbands with another family and at the same time not caring for the family back home. Bildt and Michelsen (2002) concur with some of these findings by stating that occupational factors such as no education at the employer's expense, low occupational pride, low stimulation at work and poor social support were related to poor mental health among women. Non-occupational factors related to poor mental health among women were poor quality of social contacts, demanding life events, physical inactivity and inadequate coping strategies.

\section{Mental health and youth}

The young people in the study appeared to be more forthcoming about issues of mental health than the adults. They identified depression and addiction as the main mental health problems. They expressed the view that unemployment, stresses of life and HIV/AIDS as the main source of mental health problems amongst the youth. They stated also that there was a high sense of hopelessness amongst youths. Girls reported issues of sexual abuse as a major problem, stating that they felt insecure because of lack of support from the families. In some cases the perpetrators of the abuse were family members. 


\section{Mental health and children}

Reports on the prevalence of poor mental health in children were obtained mainly from the school teachers. They expressed the view that, although some parents try to shield their children from the impact of some of the poor socio-economic conditions in the area, ultimately it is the children who suffer. The school teachers reported that there are mental health problems amongst the school children, mainly in the form of depression. The teachers usually recognise depression when a child changes behaviour or in some cases suddenly withdraws or displaced aggression towards his/her peers and teachers. In addition, educational performance deteriorates. They indicated that the problem was that people do not speak out; they rather endure the difficulties. For example, a child who was HIV positive was asked by his parents to ask the teacher not to teach them about HIV, because they were worried about the stigma at school.

\section{Mental health and HIV/AIDS}

According to Freeman from the Human Sciences Research Council (HSRC) (in Brits, 2004b:18), HIV/AIDS will have an increasing impact on the mental health of South Africans. Only an estimated 5\% of South Africans have undergone HIV testing; the main reasons preventing people from undergoing HIV testing could be fear of positive diagnosis and stigma. AIDS Weekly states that $80 \%$ of HIV-positive people experience symptoms of anxiety and depression. Anti-retroviral medicine has got a positive influence on mental health of HIV/AIDS persons. It is estimated that between $45 \%$ and $65 \%$ of AIDS patients experienced delirium in the later stages of the illness. Between $4 \%$ and $18 \%$ of AIDS patients experience major depression and AIDS mania in the later stages of the illness. The impact on the mental health of women has an additional dimension; the trauma of knowing that you are going to leave children behind, especially if you are the only breadwinner, is immense.

The high levels of depression reported by participants in this research corresponds with both the poor socio-economic conditions and the high incidence of HIV/AIDS.

\section{MENTAL HEALTH TREATMENT}

\section{Access and entitlement to treatment}

When discussing mental health treatment, it is important to take account of the question of entitlement and access to health service provisions. At the same time, when discussing access, it is important to distinguish between entitlement and access. Entitlement refers to rights through the legal system - the permission and benefits that an individual is entitled to. In terms of health services, including mental health services, everyone who is legally resident in South Africa is entitled to use the South African Health Service (National Health Bill, Chapter 1; Health Sector Strategic Framework, 2000-2004; Patients Rights Charter, point 3, Access to health care). It became evident through the interviews in the study that the high influx of migrants who reside in the mining communities includes a mixture of documented and undocumented migrants. In addition, it also includes the dependents of migrant labourers who have come for short visits. Undocumented migrants and dependants of migrants without IDs are not entitled to free treatment in the South African health service. Therefore they have to rely on the private sector. However, not everyone who is entitled has access to the mental health service. The dictionary definition of accessibility includes "easy to approach, enter or use, available, understandable". Bellaart (2003) suggests that for a service to be accessible, it must have some of the following features: it must be well known; open; friendly; nearby; trustworthy; recognisable; competent and have a good image. Therefore, access to mental 
health care is more than just being able to get in, but it is also about finding it appropriate for one's needs.

\section{Service provisions}

One of the core issues when looking at mental heath problems in the mining environment is the poor service provisions as well as the access to them.

The health care provisions and facilities in the area are as follows:

- One mine hospital;

- One mine clinic;

- One government clinic per village, except for the more affluent area where there is a mobile clinic once a week and a number of private practitioners;

- One government hospital in Rustenburg (about 40 kilometres away from the research setting);

- Traditional healers (the government has incorporated traditional healers into the health system to improve access. Some clinics reported that they have a complementary working relationship with the traditional healers);

- One rescue home for abused women and children.

With regard to the mine hospital and clinic, only permanent employees of the mine are entitled to, and have access to, those services. Consequently dependents of mine employees have to rely on either government clinics or the private sector. According to the Manager: Medical Services of the mine, permanent mine employees do not pay at the mine for medical facilities. For some occupational positions (mainly white employees) this facility is extended to their dependants and they are also assisted with medical aid, which enables them to access private health care. Community members who do not work for the mine and dependants of employees in the lower occupational positions (mainly black employees) do not access the mine hospital or clinic unless it is an emergency. These people have to use government facilities, which are overcrowded and not as adequately equipped or able to deal with the increased demand for the service generated by migration to the area for mine employment. On the other hand, $99 \%$ of the white employees have access to medical aid; therefore they have a choice where to go for treatment. The implication of this is that additional patients not accounted for by government structures are overburdening government clinics. Furthermore, in some cases the conditions at the government clinics are very poor, e.g. one clinic catering for 20000 local people also has to cater for a substantial number of contract workers from the mine with a basic staff compliment of six professional nurses, three nursing assistants, one medical doctor, who once a week sees a maximum of seven patients, and a social worker (twice a week). The clinic is located in a building that was once used as a police station. The impact of these inadequate provisions on the communities is that in order to be seen at the clinic, people have to be in the queue from 5:00 am because the clinic can manage to see only 50 people per day.

In terms of mental health the clinic had an allocation of one mental health nurse. However, at the time of the survey there was no mental health nurse, because she had resigned. Mining areas generally suffer from chronic shortages of mental health professionals. Specialty providers in mental health are highly unlikely to be available in isolated mining areas and a comprehensive service is often not available. There appears to be a lack of a mental health plan for the mining communities; consequently there is a lack of sustained effort to prepare and deploy professionals for mining practice. There seems to be an assumption amongst the planners that the urban models of care for mental health will also work in mining communities. 
The study found that the mental health services were poorly staffed and with poor or nonexistent facilities. For example, one social worker was responsible for looking after two villages and was sub-contracted by a non-governmental organisation (NGO). This social worker's responsibilities ranged from, amongst other things, all interventions such as counselling for pre-HIV testing, domestic disputes, assessment for food parcels, child-abuse issues, group work, mental health assessments, counselling and foster parent assessments. The social worker reported that, although she found the work rewarding, she felt that she was overworked and was not happy with her working conditions. She expressed that it did not surprise her that some of her colleagues were opting to go overseas, where they were remunerated fairly.

What is interesting about reports of mental health in these communities is what was not said. For example, a sister at one of the clinics stated that "there are a large number of people on schizophrenic medication. These medications include largactile, epilim and chlopixol. We give the medication to the clients and they return home. They have regular contact with care givers in the communities." What is interesting about this is that, throughout the survey, there was no mention of ongoing assessments and reviews of clients with mental health problems from the medics. The blood tests that were undertaken for most community members were mainly to check their HIV status. In terms of risk assessment for both the schizophrenic clients and the communities there appears to be a low level of mental health professionals in this area to undertake optimum assessments, reviews and monitoring of clients who are prescribed these medications. The nature of schizophrenia and the medication prescribed require that mental health specialists maintain close monitoring of the clients in terms of blood tests, compliance, side effects, client reactions and appropriateness of the medication. Care givers are not trained to undertake such assessments. Lack of knowledge and support, and poor resources and advocacy mean that some of these clients have remained on these medications without reviews from mental health clinicians. What was also interesting was that no one in the communities described observing or ever experiencing psychotic episodes. Most of the mental health described in this survey related to mood disorders. A further observation is that in a community with high alcohol and dagga abuse and violence, it is surprising that there was no mention of alcohol dementia or delirium tremors either by the community members or medical staff. It is likely that some of the violence may be related to mental health problems.

\section{Pathway to service}

Goldberg and Huxley's (1980) pathway to psychiatric care is a helpful frame of reference with which to compare themes emerging from multicultural access to mental health services. They propose a five-stage model of the route from first experiencing symptoms to arrival to secondary care. They argue that each stage could be considered as a selectively permeable filter, with some individuals having greater ability to pass through the filter than others do. This article will focus on three stages relevant to the communities, namely:

- community

- assessment

- therapeutic interventions.

\section{Community}

For a person to approach a mental health service, they have to define what is happening to them as a mental illness. At this point it is worth drawing attention to the distinction between disease and illness, which can determine help-seeking behaviour. Disease refers to a malfunctioning of biological and/or psychological processes, while the term illness refers to 
the psychosocial experience and meaning of perceived disease (Emson, 1987). Kleinman (1980) emphasises that illness is the shaping of disease into behaviour and experience created by social, personal and cultural reaction to disease. This distinction between disease and illness is absolutely crucial when trying to understand the pathways taken when seeking help. The development of disease into illness (at the individual level) and the provision of acceptable services (at the healthcare system level) are linked in determining the pathway that a patient may follow when looking for help. The definition of mental illness in the South African context is not as wide as the Western model. Mood-related mental disorders such as anxiety and low mood do not constitute mental illness, as in the Western perspective. Most people in the communities link such distress to the social and economic pressures they are experiencing and would either cope with these feelings or normalise the distress (Fenton \& Karlsen, 2002). Mining community members do not always medicalise mood disorders or conceptualise medical help seeking. It is only when they reach breakdown point that they will seek help. The pathway to that help is not always the mainstream health care system. Community members have several options that they use and these include social networks, church leaders and traditional healers. Those who are migrants may choose to return home to use the system, which they feel understands their explanatory model. By this time it is likely that the extended family would be involved. Even if they recognise that they have mental health problems, they are less likely to understand their care options in terms of the health service provisions. At the same time, even if a member of the community medicalises these disorders, there is an element of fear of being stigmatised. Generally in these communities there is more sympathy for someone who has an alcohol problem than mental health problems. In addition, the service provision is such that, if you are seen receiving counselling from either the social worker or the community volunteers, it is assumed that you are HIV positive.

The white communities also suffer from the impact of stigmatisation. The researchers observed that this was well entrenched in the past apartheid system. The posters outside a rescue home which is based in a white community where few black people commute - is a case in point. The manager of the rescue home reported that they mainly get white women from other areas making use of their services. Local white women do not use these services. Few black women use the service and, even if they come seeking help, their families or community elders often come to demand them back. Therefore, despite the rescue home being used mainly by white people, the posters advertising the home and the literature about the rescue home in the mine brochures use pictures of black women and children as the service recipients; this is clearly not the case. This is a disadvantage to the white women, because this type of denial by service providers reduces their opportunities for dealing with help seeking. It gives the impression that institutions also contribute to the stigmatisation of mental health problems; this can have an impact on the health-seeking behaviour of the white female population.

\section{Assessment}

Goldberg and Huxley (1980) suggest that, once a decision has been made to consult the doctor, the doctor must first detect that the patient is emotionally distressed and respond appropriately. Progression to the psychiatry services is reliant upon the General Practitioner (GP) recognising the psychiatric nature of the disorder before deciding that it is necessary to refer. Goldberg and Huxley (1980) suggested that a large proportion of psychiatric disorders are "missed" by GPs, largely because of the tendency of patients to present to their GPs with physical symptoms only. One GP in the community confirmed that a lot of her patients come in complaining of physical ailments and it is only after several consultations, when the patient talks about social issues, that it becomes apparent that the problem is a mental health issue. The problem with 
this long process of diagnosis is that most people do not get the opportunity to be diagnosed as having a mental health problem. The state of the health service in the mining communities has an impact on whether an individual has sufficient access to the doctor for the diagnosis to be made. There were many reports by participants that people were being turned away from the clinics because they were overcrowded. In addition, the doctor only comes once per week to see a maximum of seven seriously ill patients at a clinic that caters for more than 20000 people; these conditions make it unlikely that mental health problems are adequately dealt with. Furthermore, several different migrant and local groups using different languages characterise the mining communities. This can make it difficult for the doctor to ascertain the exact mental health problem. For example, the common language used in the mining communities is Fanagalo, which has a total of 500 words, most of which are mining operations-based words; it is unlikely that a language with such a limited number of words can enable a person to provide a clear description of their condition. These communication problems can lead to misdiagnosis and result in either wrong therapeutic interventions or loss of confidence or interest on the part of the patient; consequently, they are not able to access mental health services.

\section{Therapeutic intervention}

Once a diagnosis has been made, the patients are referred to the social worker for counselling. They normally have to wait months to be seen and by that time conditions have become worse. Some people end up seeing traditional healers and can stay with them for up to a period of three months. This route is well supported by government and should be incorporated into the health system, according to recent health policy. Although not yet formalised, some clinics are already collaborating with the traditional healers. One clinic reported that illnesses that need to be treated in cultural ways, such as issues relating to being bewitched and some STIs, are referred to the traditional healers. They reported that some of the traditional healers' herbs are very effective for some chronic STIs. Traditional healers and the clinic have an understanding in that the traditional healers are not to give medication for TB and HIV/AIDS, but provide reassurance to their clients about the service that they are getting from the clinics. The traditional healers' therapeutic interventions are unique in their approach. The traditional healer's therapeutic approach is to tell the patient what is wrong and prescribe the treatment. Ingleby (2003) and Fernando (1995) argue that the Western model focuses on what is in the "individual's head", while much of the experience of illness is connected to the societal reactions and the structure of the institutions. Most western therapies encourage patients to talk about their feelings and work out the solution; this is not popular with people from nonWestern cultures. They are more inclined to prefer the therapist who is the expert to do the talking and work out the solution. In addition, talking therapy in that form may not be popular because of language difficulties. The medical doctors do not trust the traditional healers' approach and as a result there appears to be some controversy about whether traditional healers should be involved in therapeutic interventions. The medical doctors feel that the traditional healers' approach has no scientific basis. Despite this, it is known that community members go to traditional healers. The current difficulty with involving traditional healers as part of alternative therapy is that the individual has to pay for their service, because traditional healers have not yet been fully incorporated into the national health system. If the patients' explanatory models for their illnesses require traditional healers, then integrating traditional healers into the health system will improve access. Some aspects of the Dutch mental health system incorporate traditional healers effectively to take account of the multicultural nature of their society. Integrating government, mining and traditional healers' health systems will raise 
issues relating to acculturative stress and these would need to be taken into consideration. The following are comments illustrating some of these mental health issues:

"Women experience more stress than men. This is because they are at home. They face all the family problems. If there were a place where women could go and talk they would not go. They do not want people to know how they live. However it is different with strangers. We would be prepared to get help from them than relatives. We prefer that people do not know. A hospital is better because it is not your neighbour. Each individual deals with stress differently; some use prayer, some traditional healers etc." (Community member)

"There is more stigmas against mental health than for people with alcohol problems. One man attempted suicide and was shunned by his peers. But those with alcohol problems tend to get support from their peers." (General Manager: The mine)

"Depression is usually manifested by migraine headaches. This is usually picked up after several consultations. When the patients start to talk about their social backgrounds, then it becomes apparent that the problem is a mental health issue as opposed to a physical problem. Stress in women is usually related to what their husbands are up to or the husbands' finances i.e. not knowing how much and not being involved in the decision making in terms of finances. Children come with heart problems [query anxiety]. Again the social background and history give you an indication of what is going on with the child. Children are usually brought in because they have fainted at school or they have had a serious asthma attack, which is not reflected in the physical examination." (General practitioner in the community)

"There are cases of suicides in the communities. This normally takes place when people have been informed that they are HIV positive. This occurs mainly when the person is a parent. They do it because they feel that they have let their family down. The youth can also commit suicide or be suicidal because of HIV." (Volunteer for the HIV/AIDS program)

"There are people who believe that they will only survive by taking tablets and there are people who believe that they can only survive by using roots. The mine should recognize this. We are also here to check and remedy any illnesses. The mine should send people to us because some people can die because the mine does not refer them to us. Recognising us is important because there are some illnesses related to our culture, such as being bewitched, which the white hospitals cannot deal with. They either do not understand them or do not recognise these illnesses. Because we understand them we can deal with such illnesses. The problem is that most people would never report this in the mine hospital because they are scared. There is a lot of this." (Traditional healers)

"In this community issues such as poverty, unemployment, and family problems are the main issues behind mental health illnesses." (Community member)

\section{RECOMMENDATIONS}

At this point it can be argued that by reducing the social risk factors (migrant labour issues, poverty and unemployment, HIV/AIDS, infrastructural shortcomings), there will be a high probability of improvement in family disorganisation and mental health (Patel, 2001). 
More specifically the approach to the recommendations will be twofold: firstly, issues related to social responsibilities in the mining communities; and secondly, improvement to access to mental health services and provisions.

\section{Social responsibilities in the mining community}

The literature review suggests that there is a constant "tug of war" between government and the mining companies with regard to responsibilities for welfare issues in the mining communities (Pasco-Font, 2002). The implications of this "tug of war" have been that the socio-economic issues for the communities have been left unchecked at the expense of the communities. Consequently a clear split of responsibilities between government and the mining company should be set in order to facilitate improvements in the socio-economic conditions in the mining communities. Currently, the government has instituted the Mining Charter (2002) as well as the Mineral and Petroleum Resources Development Act (MPRDA 2004) as guidance and monitoring instrument for social responsibilities in the mining sector.

In the case of the mining company, it is important that it should recognise that it has had a role in disrupting the livelihood of the local members of the communities through its operations and must contribute towards redressing some of these issues. The survey under scrutiny in this article found that the majority of community members felt that the mining company had a responsibility to improve issues related to migrant labour, poverty and HIV/AIDS. Some community members felt that it was the mining company's duty as a corporate citizen and profit-making organisation to plough back some of these revenues to the community. These sentiments are echoed by the Mining Charter (2002) as well as by the MPRDA (2004).

Government, on the other hand, should recognise that the mining communities suffer disproportionately compared to their urban counterparts. But at the same time these communities are custodians of the mineral-rich land from which the government receives a large proportion of tax revenue. It makes sense that some of this revenue should be ploughed back to these communities to address the disadvantaged nature of the communities. In addition the government, in recognising the disadvantaged nature of these communities, should provide incentives for service providers such as nurses and social workers to encourage them to want to relocate and work in these communities. Currently service providers such as nurses and social workers are prepared to migrate to other countries because of better remuneration and benefits. The government can go a long way to keep some of these important skills in the country.

Traditional leaders have access to royalties, which they can use to improve some aspects of the mining communities. The research found that some community members felt that they were let down by their traditional leaders.

So far the discussion has been about the risk factors faced by community members and their vulnerability. Some survey participants in this study argued that some of the extreme measures taken by some members (in the name of survival) of the communities cannot totally be blamed on the community circumstances, but attitudes of some of the community members and their inability to prioritise. It is acknowledged that the process that most community members are going through is a difficult one, but with support within the communities these problems can be avoided.

\section{Improvements in access to mental health services and provisions}

In terms of improving access and help seeking to mental health care/provision for the members of the mining communities, some of the following limitations have been identified: nationally 
there is one mental health strategy that is set up to fit all circumstances (regardless of region, culture and economic environment); mental health care is seen as optional rather than a mainstream issue such as physical health problems; planning in mental health services appears to be based on what pays rather than on what works; members of the mining communities enter the mental health care later, sicker and consequently with a higher level of cost; there are limited, inadequate or non-existent mental health professionals within these areas; there are few programmes that train professionals to work in mining communities and at the end of the day members of the mining communities lack any choice of health service providers, let alone mental health care providers.

Watters (2003) suggests that the way forward in mental health service provisions is to identify elements of good practice and implement them. He further suggests that elements of good practice include: access to services, both actual and planned; user involvement; multi-agency linkages; continuity of services for clients; sensitivity; advocacy; research and evaluation. Achieving change can be analysed at three levels: macro, meso and micro. In adapting the analytical approach proposed by Pilgrim and Rogers (1993), the macro level here refers to national policy frameworks in view of all the factors that affect mental health services in the country. Analysis at this level looks at the influence of policy guidance for the achievement of projects. The meso level refers to the project's relationship to its various constituent parts and to local configuration of services. The micro level refers to the impact of the project in its direct relationship with the clients it seeks to serve. Successful improvement in service requires good integration of the macro, meso and micro level.

\section{Macro level}

At present, there is no national strategy or policy specifically intended to improve either the mental health in mining communities or their care and treatment. Most approaches taken to address these problems have been either fragmented or selective. As a result the members of the mining communities have tended to be marginalised or ignored. There is therefore a need to set up a mental health strategy and initiative that is sensitive to regional, economic and cultural differences. The problems associated with culture and mental health are complex. Progress and change in this area are dependent on an inclusive process, involving politicians, policy makers, service providers from both the mainstream mental health services, traditional healers, private and voluntary sector, service users, carers and most importantly the community members. The survey results from this research have shown that the role players often have funding problems. Policy strategies focused at marginalised groups would stand a better chance of success with better financial backing.

\section{Meso level}

With regard to the meso level, structural integration is a very important factor. Structural integration involves the coordination of all the services in the locality. This is important because there is a great deal of variation from locality to locality. The important aim is to engage all the role players with the mainstream mental health providers without any party being marginalised. The programmes should be set up to raise awareness of mental health issues in the community and to demystify mental illness and encourage people to seek help. It is also an opportunity for mainstream mental health professionals to get a better understanding of the various community definitions of mental illness and how each group approaches treatment. Such programmes must be designed and established in conjunction with the communities concerned, so that the content, language, tone and delivery mechanisms meet the needs of the communities. There is a need for a range of responses and products including: 
materials, written and multimedia information, specifically designed for the communities. Characteristics of the programme must include: community involvement and ownership; adequate and sustained funding; use of relevant settings (e.g. churches, clubs community press); relating the programme to wider health-promotion initiatives such as addiction and HIV/AIDS; establishment of local service information; a range of communication mechanisms and evaluation of the programme which involve the local community. The aim of the evaluation should be to provide service improvement and not be a way of delaying project funding or proving a point (Fernando, 1995). The agendas of the evaluation must be made clear. Families and carers should be included in the programme because they play an important role in the help-seeking process, but often face a number of difficulties in gaining access to appropriate services (Keating, Robertson, McCulloch \& Francis, 2002).

From this survey in the Rustenburg area it was clear that the traditional leaders, communities and religious groups are interested in collaborative work. However, there were no suggestions on how to achieve this. There is a need to initiate co-operation between the interested parties not only to avoid duplication, but also competitiveness and antagonism towards those that are well-funded by those that are not (Patel, Wardle, Bashford, Fountain \& Sheikh, 2001). When diverse cultures come together for a collective effort in a project, culture shock could be experienced. Sohmen (2003) argues that acculturative stress, which can be defined as jobrelated stress that is exacerbated by cultural differences such as diverse assumptions, values and beliefs among participants, can be an impediment to the success of the project. Zetter and Pearl (2000) found that rationalisation by mainstream services makes it difficult for traditional leaders, communities and religious groups to work in partnership with mainstream services. Mainstream services work within certain policy guidelines that set the standard of operation and set targets that are difficult for the traditional leaders, communities and religious groups to work with because they are more task orientated. This can result in co-opting the other parties rather than developing a partnership. Taylor (2000) notes that many community groups feel they are consulted only to fulfil central government requirements. Patel et al. (2001) have observed that such initiatives allow too little time for capacity building.

Some of the positive actions that can be taken to minimise acculturative stress are outlined below. The community groups should be involved in strategy and policy development and programme delivery. It must be ensured that the community groups are represented on the steering groups and management structures can facilitate a partnership, rather adopting than commissioning agency approach. Improved but realistic contracts should help to: clarify roles and responsibilities; set a framework for monitoring and more professional ways of working; and ensure clearer accountability. Staff training needs are paramount; this applies to both sectors and all levels of staff. Student placements should include placements in communities to increase exposure and understanding of mining community issues. With increasing volumes of work and lack of professional and managerial capacity, there are clear indications that if community groups are to be more than gap fillers, then they must review their human resources needs and undertake a substantial upgrading of the skills base. In this way, partnership and not co-opting can be achieved.

\section{Micro level}

Improved communication between the mainstream service providers and the local community organisation will facilitate better interaction with the clients. By sharing information, clients can be referred to appropriate services within the area. The choice of services is improved, because there is more information and knowledge about what is available. Appropriate training and funding for all community groups and mainstream service providers mean that there will 
be improved therapeutic interventions, taking account of the explanatory models and being sensitive to cultural issues without stereotyping the service users. Collaborative work can improve access for those with language problems by way of improving interpretation services and increasing the opportunity for therapeutic interaction in the client's language. People express their feelings better in their own language.

\section{CONCLUSION}

The study has shown that the mining environment is a "breeding ground" for family disorganisation and mental health, but yet the issues, although important, are to a great extent ignored. As stated above, socio-economic conditions lie at the root of these problems. What also came clearly from the results of the survey was that until issues related to social responsibilities are identified and good working partnerships are formed, these conditions will remain.

Lastly, the survey found that the nature of mental health makes it an underestimated health problem in the mining communities; Schlebusch (Padayachee, 2003) duly states that "blood and gore are more tangible than the slow decay of the mind."

\section{REFERENCES}

BEKKER, S.B. \& SWART, K. 2003. The relationship between migration and the HIV-AIDS pandemic: a preliminary South African analysis. In: COHEN, R. (ed) Migration and health in Southern Africa. Cape Town: Van Schaik: 63-68.

BELLAART, H. 2003. Accessibility of child and youth care for migrants and refugees. International Workshop: Service provision for migrants and refugees. University of Utrecht, Utrecht, The Netherlands.

BILDT, C. \& MICHELSEN, H. 2002. Gender differences in the effects from working conditions on mental health: a 4-year follow-up. International Archives of Occupational and Environmental Health, 75(4):252-258.

BRITS, E. 2004a. Unicef maan oor vigswese in SA ["Unicef warns of aids orphans in SA"]. Die Burger, 6, December 10.

BRITS, E. 2004b. Vigs tref die gees toenemend in SA ["Aids is increasingly affecting the spirit in SA"]. Beeld, 18, October 15.

BROAD-BASED SOCIO-ECONOMIC EMPOWERMENT CHARTER FOR THE MINING INDUSTRY. 2002. South African Government: Pretoria.

CAMPBELL, C. \& MZAIDUME, Y. 1999. Social capital and grassroots participation in community health projects. Paper presented to the First International Conference on Critical and Qualitative Approaches to Health Psychology. St Johns, Canada.

CHENGA, C.S., CRONJé, J.F. \& THERON, S.E. 2006. Critical factors for sustainable social projects. Journal of the South African Institute of Mining and Metallurgy, 106(1):57-61.

CRESWELL, J.W. 1994. Research design: qualitative and quantitative approaches. Thousand Oaks: Sage.

CRONJé, J.F., CHENGA, C.S. \& NAUDé, A.M.E. 2005. Community Development Needs, conducted as Phase 3 of a Stakeholder Perception Survey for Lonmin Platinum. Research report. Potchefstroom, South Africa. 
DE VILLIERS, J. 2005. Vigssterftesyfer sal bly styg, al doen Afrika-regerings wat [“Aids death figure will keep on rising despite efforts of African governments"]. Beeld, 4, March 4.

DU PREEZ, L. 2004. Tieners glo swanger om toelae te kan kry [“Teenagers are apparently getting pregnant to get income support"]. Beeld, 13, November 3.

EMSON, H.E. 1987. Health, disease and illness: matters for definition. [Web:] Available: http://www.pubmedcentral.nih.gov/pagerender.fcgi?artid=1492114\& pageindex $=1$ [Accessed: 22 January 2007].

FENTON, S. \& KARLSEN, S. 2002. Explaining mental distress: narratives of cause. In: O'CONNOR, W. \& NAZROO, J. (eds) Ethnic differences in the context and experience of psychiatric illness: a qualitative study. London: The Stationary Office.

FERNANDO, S. 1995. Mental Health in a multi-ethnic society: A multidisciplinary handbook. London: Routledge.

GOLDBERG, D.P. \& HUXLEY, P. 1980. Mental illness in the community. London: Tavistock.

GYLFASON, T. 2001. Natural resources, education and economic development. European Economic Review, 45(4-6):847-859.

HARPHAM, T. 1994. Urbanisation in mental health in developing countries: a research for social scientists, public health professionals and social psychiatrists. Social Science \& Medicine, 39(2):233-245.

HEALTH SECTOR STRATEGIC FRAMEWORK: 2000-2004. [Web:] Available: http://legacy.hst.org.za/doh/stratplan.htm. [Accessed: 22 January 2007].

HELP AGE INTERNATIONAL. 2004. HIV/AIDS: who cares? Ageing and Development, 16:1-12, June.

INGLEBY, D. 2003. 'Goodness of fit' between service providers and clients. International Workshop on service provision for migrants and refugees. Utrecht, The Netherlands.

KEATING, F., ROBERTSON, D., McCULLOCH, A. \& FRANCIS, E. 2002. Breaking the circle of fear: a review of the relationship between mental health services in African and Caribbean communities. The Sainsbury Centre for Mental Health, UK.

KLEINMAN, A. 1980. Patients and their healers in the context of culture. Berkeley, Calif.: University of California Press.

KREFTING, L. 1991. Rigor in qualitative research: the assessment of trustworthiness. The American Journal of Occupational Therapy, 45(3):214-222.

KVALE, S. 1983. The qualitative research interview: a phenomenological and a hermeneutical mode of understanding. Journal of Phenomenological Psychology, 14:171-196.

LE ROUX, M. 2004. MIV ondergrawe mynwinste ["HIV undermining mine profits"]. Sakebeeld, 1, November 26.

MBENDI PROFILE SOUTH AFRICA MINING-OVERVIEW. 2002. Mbendi Information for Africa: an electronic journal. [Web:] Available: http://www.mbendi.co.za. [Accessed: 26 August 2004].

METCALFE, M. 2003/2004. AIDS in the mining industry. Investment, Mines \& Quarries. Africa \& International. Rivonia, South Africa. 
MEYERS, J. 1999. The Spontaneous Ideology of Tradition in Post-Apartheid South Africa. Politikon, 26(1):33-54.

MILLER, D.E. 2000. Mathematical dimensions of qualitative research. Symbolic Interaction, 23(4):399-402.

MINERAL AND PETROLEUM RESOURCES DEVELOPMENT ACT (MPRDA). Act 28 of 2002. Amendment (Gazette 26942, Regulation Gazette 8087). 29 October 2004. South Africa.

MOHALE, J. 2001. Chiefs ask for land rights. Sowetan, June 5.

MULDER, N. 2007. SA het meeste Vigswesies ["SA has got the most Aids orphans"]. Beeld, 12, January 18.

NATIONAL HEALTH BILL. 2003. [Web:] Available: ftp://ftp.hst.org.za/pubs/ govdocs/bills/nathealthbill.pdf. [Accessed: 22 January 2007].

PACKARD, R.M. 1989. White plague, Black labor: tuberculosis and the political economy of health and disease in South Africa. Berkeley, Calif.: University of California Press.

PADAYACHEE, N. 2003. Our children are choosing death. Sunday Times, November 2.

PASCO-FONT, A. 2002. Distribution of mineral wealth in Latin America: Case studies in the Andes. Resourcing the future, GRADE: Toronto, Canada.

PATEL, K., WARDLE, I., BASHFORD, J., FOUNTAIN, J. \& SHEIKH, N. 2001. A review of current drug service provision for Black and minority ethnic communities in Waltham Forest and Redbridge. Final report on a needs assessment for Waltham Forest and Redbridge Drug Action Teams. Preston Centre for Ethnicity and Health, Faculty of Health, University of Central Lancaster, UK.

PATEL, W. 2001. Poverty, inequality and mental health in developing countries. In: LEON, D. \& WALT, G. (eds) Poverty, inequality and health. Oxford: Oxford University Press.

PATIENTS RIGHTS CHARTER. [Web:] Available: http://legacy.hst.org.za/doh/rights chart.htm. [Accessed: 22 January 2007].

PATTON, M.Q. 2002. Qualitative research \& evaluation methods $\left(3^{\text {rd }} \mathrm{ed}\right)$. Thousand Oaks, Calif.: Sage Publications.

PILGRIM, D. \& ROGERS, A. 1993. A sociology of mental health and illness. Buckingham: Open University Press.

ROSSOUW, M. 2005. Meer sterf glo aan vigs as wat SSA sê ["More are dying than said by SSA"]. Beeld, 6, March 16.

ROSSOUW, M. \& DE LANGE, L. 2004. Belofte: geen plakkers in SA oor 10 jaar ["Promise: no squatters in SA in ten years time"]. Beeld, 5, September 3.

RUSSELL, S.C. \& McDONALD, M.B. 1982. The economic contributions of women in a Rural Western Navajo Community.

RUSSELL, S.C. \& McDONALD, M.B. 1982. The economic contributions of women in a Rural Western Navajo Community. Available: http://www.jstor.org/view/0095182x/ap040021/04a00140/0. [Accessed: 16 January 2007]. 
SCHOOFS, M. 1999. All that glitters: How HIV caught fire in SA: Part one: sex and the migrant miner. The Body: An Electronic Journal. Available: http://www.thebody.com. [Accessed: 28 August 2004].

SHAHAB, Z.S. 2005. Poverty, family stress \& parenting. Available: http://www.humiliationstudies.org/documents/AhmedPovertyFamilyStressParenting.pdf. [Accessed: 16 January 2007].

SOHMEN, V. 2003. Acculturative project stress. Umed School of Business and Economics, Umed University, Sweden.

TAYLOR, M. 2000. Maintaining community involvement in regeneration: what are the issues? Local Economy, 15(3): 251-267.

UNSTED, A.D. 2001. Airborne pollutants. In: GUILD, R., EHRLICH, R.I., JOHNSTON, J.R. \& ROSS, M.H. (eds) SIMRAC Handbook of Occupational Health Practice in the South African Mining Industry. Braamfontein: The Safety in Mines Research Advisory Committee (SIMRAC): 85-118.

VAN WYK, A. 2004. Nuwe bier in ou kalbasse ["New Beer in Old Calabashes"]. Beeld, March 11.

WATTERS, C. 2003. Good practices for asylum seekers and refugees. International Workshop: Service provisions for migrants and refugees. Utrecht, The Netherlands.

ZETTER, R. \& PEARL, M. 2000. The minority within the minority: refugee community-based organisations in the UK and the impact of restrictionism on asylum-seekers. Journal of Ethnic and Migration Studies, 26(4):675-697.

Ms Charity Chenga, University of Kent, United Kingdom and Dr Freek Cronjé, Department of Sociology, North-West University, Potchefstroom, South Africa. 